\title{
Tax reforms and Google searches: the case of Spanish VAT reforms during the great recession
}

\author{
Joaquín Artés $^{1}$ - Ana Melissa Botello Mainieri ${ }^{2}$ A. Jesús Sánchez-Fuentes ${ }^{1,3}$ (D
}

Received: 15 February 2019 / Accepted: 14 August 2019 / Published online: 27 August 2019

(c) The Author(s) 2019

\begin{abstract}
We propose a method to capture the effect of tax reforms on consumer's readiness to buy using Google searches as a proxy. We use the Spanish 2010 and 2012 VAT reforms as a case of study. We use a regression discontinuity design taking advantage of the fact that the Spanish 2010 and 2012 VAT reforms had a sharp implementation date, which implies that from one day to another the tax rate for most goods was different, while other factors likely to influence consumer behaviour were similar on the days around the cut-off. We find a significant causal effect of the implementation of the reform on Google searches of durable goods, while we do not find any effect for non-durable goods. These results are in line with previous theoretical and empirical evidence according to which tax reforms cause consumers to modify more their readiness to buy durable goods. We also explore the effect of the reforms on readiness to buy specific goods such as movie tickets by taking advantage of a control group formed by similar leisure items that were unaffected by the 2012 reform.
\end{abstract}

Keywords Private consumption · Value-added tax · Indirect taxation · Unconventional fiscal policy $\cdot$ Google Trends $\cdot$ Big data

JEL Classification H3 $\cdot$ H43 $\cdot$ D04

A. Jesús Sánchez-Fuentes

ajsanchezfuentes@ucm.es

1 Instituto Complutense de Estudios Internacionales, Universidad Complutense de Madrid (UCM), Madrid, Spain

2 Universidad Complutense de Madrid (UCM), Madrid, Spain

3 GEN-UVigo, Vigo, Spain 


\section{Introduction}

There is a consensus about consumers being quite sensitive to changes in the economic context in which they purchase goods. Tax reforms are an example of shock to the economic environment likely to affect consumer's purchasing behaviour and the economy overall (e.g. in Spain consumption represents $60 \%$ of GDP).

There are many channels through which tax reforms could affect consumption patterns. In this paper, we focus on the short-run intertemporal substitution of consumption. When a new tax increase is announced, consumers have an incentive to buy the goods for which the tax rate will be higher once the reform is in place and to delay the consumption of goods for which the tax rate will be lower, which changes overall spending in the economy [see, for example, Shapiro (1991), Feldstein (2002), and Hall (2011), among others]. In addition, the degree to which a tax reform causes some intertemporal substitution should depend on how elastic the consumption of certain goods is over time. In this regard, there is a difference between durable and non-durable goods, as the specific date in which consumers buy certain durable goods can be easily adjusted, while the purchase of some non-durable perishable items may not be delayed easily.

The short-term effects of tax reforms are difficult to analyse in a timely manner as most data on consumption are released many months after the tax reform actually took place and at a level of aggregation that does not allow for the studying of short-term patterns of intertemporal substitution. For example, many official data on consumption only offer monthly data on certain aggregated baskets of goods (not on specific types of goods), and the information is released only several months after than the consumption actually happened.

In this paper, we explore the usefulness of Google searches to analyse the effect of tax reforms on short-term intertemporal substitution of consumption. Google searches are a proxy for consumer's readiness to buy certain types of goods, ${ }^{1}$ and, unless other types of data have the advantage of offering easy-to-access timely information of such patterns.

We analyse the impact of the 2010 and 2012 Spanish VAT reforms. We use these reforms as a case study as they implied the largest tax increase worldwide at the time, according to a study prepared by the KPMG (2013). In addition, the specific timing of the implementation of the reform allows us to distinguish the potential short-run effects of the announcement of the reforms from the actual implementation. This is interesting because some authors have argued that VAT reforms announcements can themselves stimulate the economy in the short term due to intertemporal patterns of substitution of consumption which may occur months before the tax rates are actually changed, when the announcement takes place. As the Spanish VAT tax reforms of 2010 and 2012 were announced several months before their implementation date,

\footnotetext{
1 While Google searches may not be a good proxy for actual consumption, they have been considered a reasonable one for consumer's readiness to buy certain types of goods, which in turn could be argued that is correlated with consumption behaviour. See, among others, Della Penna and Huang (2009), Camacho and Pacce (2018) and Gil et al. (2018).
} 
we can test whether readiness to buy changes at the announcement date or closer to the actual implementation date, when relative prices do change.

Consistent with previous literature's predictions, we find that both VAT reforms have a significant negative effect on consumer's readiness to buy durable goods. We also find that the reforms did not have any impact on the readiness to buy nondurable goods. Finally, inconsistent with some previous literature, we find that the announcement of the tax change several months before the implementation date does not alter consumer's behaviour. Only around the weeks before the implementation date, we observe a pattern consistent with intertemporal consumption substitution.

\section{Background}

In this section, we provide some background on the potential effect of tax reforms such as the Spanish VAT reforms on readiness to buy certain types of goods. A key feature of such reforms is that both were pre-announced months before their actual implementation date.

As several authors such as D'Acunto et al. (2016) highlight, announcing a future VAT increase changes the intertemporal relative price of goods affected by the reform. A rationale for this can also be found on Crossley et al. (2009). In this section, we present a simple analytic illustration that captures the logic followed on those papers.

We start with an intertemporal budget constraint of a consumer with a two-period planning horizon:

$$
W=c_{2}\left(1+t_{1}\right)+\frac{1}{1+r}\left(1+t_{2}\right) c_{2}
$$

where $W$ is wealth, $c_{i}$ is consumption at period $i, t_{i}$ is the VAT tax rate at period $i$ and $r$ is interest rate. Thus, the intertemporal relative price of consumption is:

$$
\frac{p_{1}}{p_{2}}=\frac{\left(1+t_{1}\right)(1+r)}{1+t_{2}}
$$

As Fig. 1 illustrates, an increase in the VAT rate of period 2 will induce a substitution effect as households will want to respond to the change in relative prices by anticipating now some proportion of future consumption (from A to B), because present consumption has become cheaper.

The strength of this impact will depend on the extent to which retailers reduce their prices (e.g. a pass-through rate equal or close to one would lead to stronger impact). The relevant parameter is thus the elasticity of intertemporal substitution (EIS). According to Attanasio and Wakefield (2008), a plausible range of estimates for this parameter is between 0.5 and 1 , basing their analysis on micro-data surveys. Crossley et al. (2009) point out two reasons for such low values of EIS. First, most micro-data estimates of the EIS are based on total non-durable consumption and exclude durable goods. Durable goods are likely to have a higher EIS due to their 


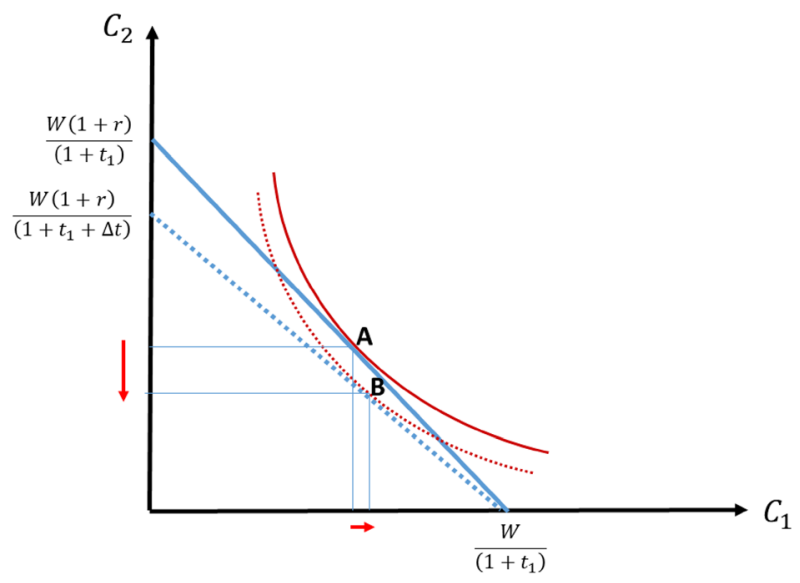

Fig. 1 Period 2 pre-announced VAT increase in a two-period model. Source: Own elaboration

durability (which breaks the link between expenditure and consumption). Second, as Browning and Crossley (2001) point out, luxuries are easier to postpone, whereas basic goods purchased today are not a good substitute for basic needs tomorrow. For instance, a purchase of a car when one's car is relatively old is easier to postpone or anticipate a few months compared to the consumption of food.

Overall, the above discussion implies that we should observe a pattern of intertemporal substitution of consumption according to which (1) consumer's readiness to buy should be higher right before the tax increase and lower right after and (2) the readiness to buy should change more for durable goods than for non-durable goods.

In the following sections, we explore whether the patterns of Google searches around the implementation date of the VAT Spanish tax reforms are consistent with these expectations.

\section{The Spanish VAT reforms of 2010 and 2012}

The value-added tax was born in France in 1948, with the purpose of increasing Government's collection capacity and thus improving public revenues. This idea spread quickly through EEC countries first and later to all the OECD countries, and having a VAT tax even became a requirement to belong to the European Union. ${ }^{2}$

In Spain, the VAT was implemented for the first time in 1986. Since then, it has become one of the main sources of public revenues. For the sake of illustration, according to a recent monthly report (AEAT 2018), the cumulative amount of VAT revenues was 29,149 million euros (40\% of total public revenues, $6.4 \%$ of GDP.

\footnotetext{
${ }^{2}$ According to the OECD (2016), the value-added tax is the largest source of income for governments around the world, where 165 countries use it as part of their fiscal policies, twice as many as 25 years. The VAT represented for $2014,30.5 \%$ of the total income for taxes in the countries that make up the OECD.
} 


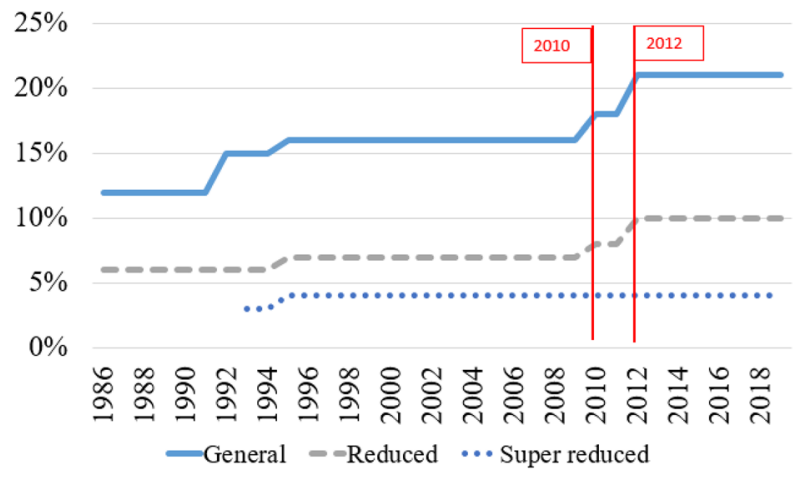

Fig. 2 Spanish VAT tax rates (1986-2019). Source: Own elaboration

Figure 2 shows the evolution of the rates of VAT in Spain. At the beginning of the period, there were three different rates: a general rate of $12 \%$, a reduced rate of $6 \%$ and an increased rate of $33 \%$. Later, in 1992, the increased rate was eliminated and a superreduced rate starting at $3 \%$ for some goods was created. Since then, there have been three main reforms of the VAT, in 1995, 2010 and 2012. As we can see in the figure, each of the three reforms leads to an increase in the tax rates during those years, while during the periods in between the tax rates stayed constant.

The reforms of 2010 and 2012 were implemented during a period of economic crisis. In 2009, Spain experienced a significant increase in public deficit, which reached a maximum of $11.1 \%$ of GDP. The subsequent process of fiscal consolidation reduced it to $6.6 \%$ of GDP by 2013 . The VAT reforms were part of the consolidation effort. Between 2010 and 2012, the value-added tax was subject to two increases equivalent to a total of five (3) percentage points, in the case of the general (reduced) tax rate. The first increase occurred in 2010 (from 16 to $18 \%$ ) and the second in 2012 (from 18 to $21 \%$ ).

The 2010 VAT reform came into effect in July, but it was announced 9 months before. Its main features were: (1) the general rate increased from 16 to $18 \%$; (2) the reduced rate increased from 7 to $8 \%$; and (3) the superreduced rate was not changed.

The 2012 reform came into effect in September, being announced just 2 months before, and it consisted of: (1) the general rate increased from 18 to $21 \%$; (2) the reduced rate increased from 8 to $10 \%$; (3) the superreduced rate did not change; and (4) lastly, some particular goods and services experienced an extra increase in their tax rate as they were moved from the reduced VAT category to the general one. Some of the goods for which this occurred were school material (from 4 to $21 \%$ ), and cinema, theatre, hairdressers, gyms and funeral services, which rose from 8 to $21 \%$. In addition, the housing tax rate (4\%) was increased from 4 to $10 \%$, although this change took place 3 months later than the implementation of the other parts of the reform (from 01 January 2013). 


\section{Data}

In order to analyse the short-run effect of the VAT reforms of 2010 and 2012 on intertemporal substitution patterns, we need data on consumption readiness. Google searches could be a proxy of such consumption readiness. Google is the most used Internet search engine in the world, with approximately 3.8 million searches per minute. For Spain, Google's market shares for 2017 reached 92.2\% according to data from Kantar Worldpanel ComTech. This makes searches in Google a likely appropriate tool to identify trends in purchase intention or "readiness to buy" and to identify consumers' responsiveness to changes in the economic context, such as large-scale changes in tax rates.

A particular tool of Google as a search engine is relevant for our purposes. Google has created a free open access tool-Google Trends- to make available to its users information on the popularity of words or phrases (keywords). This tool provides the relative amount of searches of a certain term for a given period and region. Google Trends allows to identify variations in relative values of searches of a given term. The relative values are based on a scale from 0 to 100 , where 100 represents the highest point in levels of searches performed in that period. ${ }^{3}$ This tool not only allows to download the resulting time series but also shows a graph with the evolution of searches for the term during the period of time selected.

The frequency of data is automatically chosen depending on the range of our sample period. The longer is the period selected, the lower is the frequency of data collected. For example, if we select a very long period, the data we will obtain will be monthly; for an intermediate period, the data will be weekly; and for a narrower period, the data may be daily. Our period of analysis allows for weekly data.

We construct two main measures to proxy readiness to buy. Both of them are based on a basket of representative searches of a certain category of goods. We construct one basket for durable goods and another one for non-durable goods. We follow Gil et al. (2018) to determine the relevant representative searches for each of the two categories of goods. ${ }^{4}$ Table 2 shows the keywords used in our analysis. Some of the searches reported in Table 1 correspond to goods that are not subject to a VAT tax. While the rationale for this is clear in Gil et al. (2018), as they are trying to approximate overall consumption patterns of durable and non-durable goods using Google searches, one might be concerned that including those categories in our basket of goods introduces noise, as we should not see changes in consumption of these categories compared to the ones that are taxed. This is arguable as non-taxed goods are likely affected by changes in relative prices of substitutes or complements. However, for the sake of robustness, we

\footnotetext{
3 This maximum value obviously changed when different periods and regions are considered, potentially altering the dynamic properties of resulting time series.

${ }^{4}$ In our analysis, we focus only on the comparison between durable and non-durable goods, excluding services from the analysis. Some services are more similar to non-durable goods in terms of their expected time elasticity of substitution, while some others are more similar to durable goods. For this reason, the prediction about services is unclear.
} 


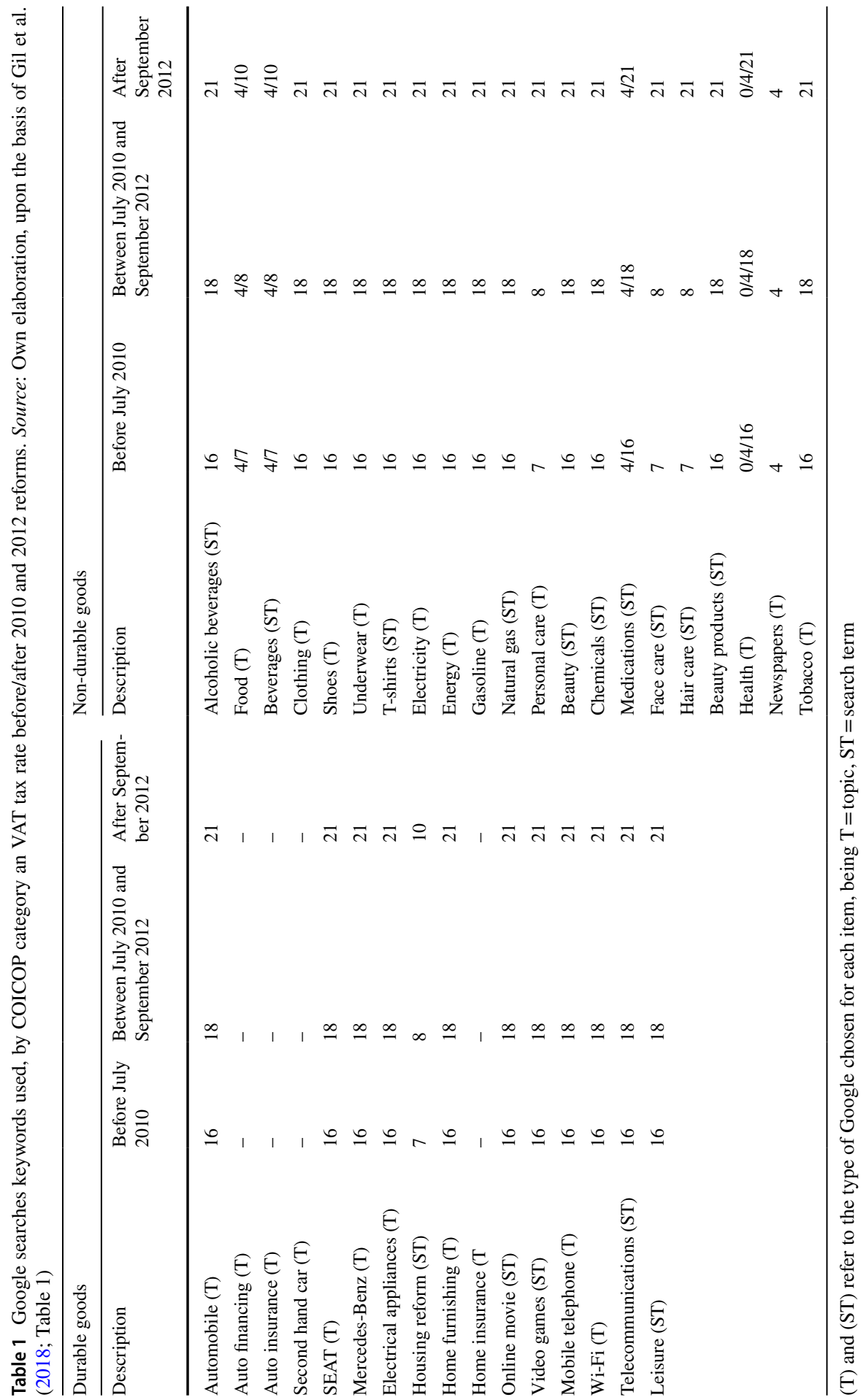


Table 2 Descriptive statistics

\begin{tabular}{llllll}
\hline Variable & Observations & Mean & SD & Min & Max \\
\hline Panel A: 2010 & & & & & \\
Average searches for durable goods & 213 & 55.62 & 4.06 & 44 & 65.38 \\
Average searches for non-durable goods & 213 & 50.35 & 3.91 & 39.71 & 59.62 \\
Average searches for "IVA" & 213 & 10.99 & 7.55 & 3 & 100 \\
After & 213 & 0.47 & 0.50 & 0 & 1 \\
Weeks & 213 & -6 & 61.63 & -112 & 100 \\
Panel B: 2012 & & & & & 67.50 \\
Average searches for durable goods & 213 & 58.38 & 3.72 & 45 & 58.52 \\
Average searches for non-durable goods & 213 & 49.59 & 3.90 & 39.29 & 100 \\
Average searches for "IVA" & 213 & 14.48 & 8.32 & 7 & 1 \\
After & 213 & 0.47 & 0.50 & 0 & 100 \\
Weeks & 213 & -6 & 61.63 & -112 \\
\hline
\end{tabular}

Panel B: July-2008 to July-2012

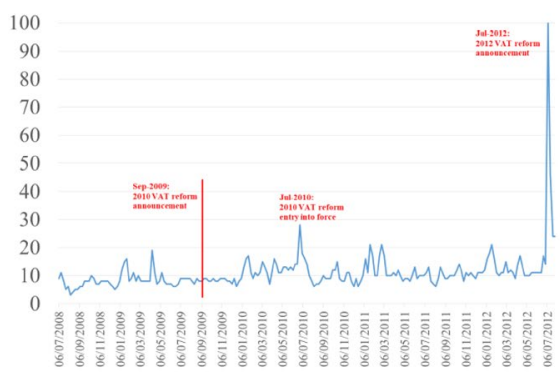

Panel A: July-2010 to July-2014

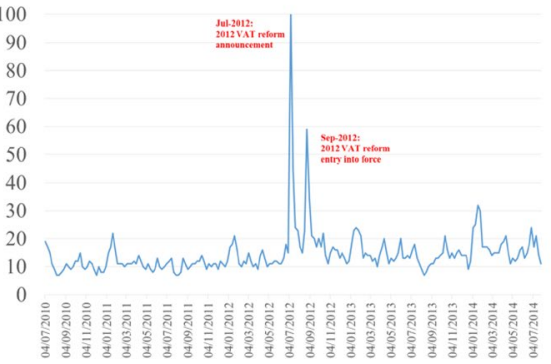

Fig. 3 Google searches for keyword "IVA" throughout the sample period (July 2008 to July 2014). Source: Google Trends

also construct an alternative basket of searches that represents the readiness-tobuy durable goods excluding the non-taxed items included in Gil et al's. The conclusions of our analysis remain the same regardless of which of the two baskets of searches we use.

Our sample period of Google searches goes from July 2008 to July 2014. Such a time period captures approximately 2 years before each of the reforms and 2 years after. As mentioned before, this choice leads to work with weekly time series, according to Google Trends operating rules.

Table 2 shows descriptive statistics of our dataset which consists of a panel of 213 observations.

Finally, Fig. 3 briefly describes how Internet searches evolved over our sample period for the keyword "IVA" (VAT, in Spanish). This table shows that there was a surge in Google searches of the word "IVA" around the announcement weeks and around the implementation weeks, pointing to consumers being aware of the upcoming changes in the tax rates of the goods that they might be considering to buy. 


\section{Empirical framework}

Our goal is to identify the effect of the reform on Google searches of certain baskets of goods that proxy readiness to buy durable or non-durable goods. Ideally, we would like to observe consumption-related searches during the period in which the new tax rates are in place (treatment period) with the searches during exactly the same period performed by a very similar group of consumers that were not exposed to the reform (control group). As this is not possible because in any given period the reform was either in place or not, we have to find a good counterfactual for the consumption behaviour of Spanish population had the reform not been implemented.

Our approach consists in using a regression discontinuity design (Angrist and Pischke 2008). The regression discontinuity design compares consumption during the control and treatment periods right around the threshold date in which the reform was implemented. As our unit of observation is weekly Google searches, our approach compares search patterns on the week prior to the starting implementation date with consumption during the implementation week. The idea of this approach is that from one day to another most economic, political or regulatory shocks on consumption are constant except for the new tax rates. Absent the reform, purchasing a product on one specific day or another is almost random over very short periods of time, which allows us to identify the causal effect of the reform on short-term intertemporal readiness to buy. The implementation of the reform implies that purchasing the product right after the threshold date is much more expensive, which would lead to a reduction in readiness to buy as proxied by Google searches of those goods compared with what would have happened otherwise.

In practical terms, the implementation of the RDD approach is equivalent to running local linear regressions of the type: ${ }^{5}$

$$
Y_{i}=\alpha+\beta_{0} f\left(\text { Weeks }_{i t}+\beta_{1} \text { After }_{i t}+\theta X_{i t}+\mathcal{E}_{i t}\right.
$$

In the above regression, $Y_{i}$ is the average percentage of Google searches in each category (compared to the week with the highest number of searches) and $\mathrm{f}$ is a polynomial of order $4{ }^{6}$ Weeks is the number of weeks before or after the threshold date, which we introduce as a fourth-order polynomial function. After is a dummy that takes value one for the weeks after the implementation of the reform and 0 for the weeks before and is our variable of interest. We would expect the coefficient of this variable to be negative and significant implying that in the period right after the increase in the VAT tax, Google searches decreased, and so did consumption. Finally, $X$ is a vector of additional controls such as monthly and geographical fixed effects.

We estimate regression [1] for both 2012 and 2010. In addition, we run a battery of robustness tests to check whether the effects we find are indeed due to the reform. In particular, we estimate the same model using as threshold date several fake dates

\footnotetext{
${ }^{5}$ A similar a approach is used in Artés and Jurado (2018). See Calonico et al. (2017) for technical details regarding its implementation in Stata.

${ }^{6}$ We have considered alternative polynomial order to check for the sensitivity of our results (see Gelman and Imbens 2017). Our results are robust to the use of other polynomial orders.
} 
such as 4, 8 and 12 months before and after the regression. The idea of these tests is that absent the reform on any given week, we should not observe drastic changes in consumption patterns, particularly once we control for other seasonal effects.

We also estimate the same model using as threshold date the announcement date. The 2012 reform was announced 2 months before the starting date of the tax increases. The 2010 reform was announced 9 months before. Therefore, we test whether the announcement itself had any impact on readiness to buy, as argued in papers such as Shapiro (1991), Feldstein (2002) or Hall (2011). As the tax rates were the same right before and after the announcement dates, we should not expect any changes in readiness to buy if consumers based their behaviour on the tax rate itself, while we should see an effect if the announcement affects short-term intertemporal substitution of readiness to buy.

Finally, we pay particular attention to studying the effect of the reform in one specific type of goods: movie tickets. The reason for this is twofold. On the one hand, we want to compare how our methodological approach works when we study a specific type of good versus when we construct aggregate measures. Second, we choose as a case study movie tickets because the VAT of leisure was increased more dramatically than that of other types of goods, from 8 to $21 \%$, and was also one of the most controversial aspects of the reform due to the intense opposition of the movie industry. In this case, we use a differences-in-differences model, comparing the evolution of the entry "movie tickets" to that of "video games", a suitable control group, as both are forms of leisure, but video games tax rates only moved from 18 to $21 \%$. We estimate the differences in differences through a regression of the type:

$$
Y_{i t}=\alpha+\beta_{0} \text { After }_{i t}+\beta_{1} \text { Treatment }+\beta_{2} \text { After } * \text { Treatment }+\theta X_{i t}+\mathcal{E}_{i t}
$$

where $Y_{i t}$ is again the percentage of Google searches in a week compared to the week with the highest number of searches. Treatment takes value 1 for movies and 0 for video games, capturing the fact that movie tickets and video games follow different searching patterns regardless of the tax rate. After takes, again, value 1 for the period right after the implementation of the reform, while $X$ is the vector of controls.

We would expect the interaction term to be negative and significant, implying that movie tickets consumption decreased compared to video games due to the causal effect of the tax reform.

\section{Results}

Table 3 shows the results of the RDD exercise. ${ }^{7}$ Each of the columns estimates the model for different types of goods. The first two columns of panel A estimate the effect of the reforms on Google searches of durable goods. As explained above, we use two different baskets of durable goods. The first basket (used in column 1

\footnotetext{
7 The tables focus on the relevant RDD parameter. The full tables corresponding to each scenario are available upon request.
} 
in Table 3) includes exactly the same categories that Gil et al. (2018) use to proxy readiness to buy durable goods overall. Model 2 excludes the searches included in Gil et al. (2018) corresponding to goods that are not subject to the VAT such as "used cars", "car insurance" or "house insurance". While the first basket likely captures overall readiness to buy better, the second focuses only on those durable goods more likely to be affected by the reform. It is not clear from the theoretical point of view which basket is preferable for our purposes, as there are pros and cons to each of them. In practical terms, however, both yield the same results: Table 3 shows that both the 2012 and 2010 VAT reforms had a statistically significant negative effect on readiness two buy. Consumers' readiness to buy durable goods as proxied by Google searches dramatically decreased from the implementation week compared to the week before. We take this as evidence of a pattern of short-term intertemporal substitution.

Column 3 of panel A shows that the reform did not have such an effect on readiness to buy non-durable goods. This is also consistent with our expectations regarding intertemporal substitution. Durable products are more time elastic, so we would expect the effect of the reform on this type of consumption to be negative. On the other hand, non-durable products like groceries are more time inelastic, which leads to consumers not changing their behaviour after the reform.

Panel B of Table 3 estimates the same models as in Panel A for a slightly different subsample. In panel A, we use the implementation week as the cut-off. The implementation day of each of the VAT reforms of 2010 and 2012, however, was not a Monday. This means that the implementation week includes both, some days with the old tax rate and some days under the new tax rates. This introduces a bias (albeit a conservative one) to our estimates which could be avoided by dropping the implementation week from the estimation sample. This is what we do in panel B of Table 3, which confirms the results of panel A. All estimates are again statistically significant for durable goods and nonsignificant for non-durable goods. In addition, and consistent with Panel A's treatment week including some non-treated days, the coefficients of panel B are now larger in magnitude.

Figure 4 shows the same effects graphically. Panel A of Fig. 1 shows the effect of both reforms on durable goods. For 2012, we can see a clear discontinuity at the threshold week and a pattern that is consistent with intertemporal substitution of consumption around the implementation weeks. (Consumers increased their readiness to buy before the start date and reduced it right after.) The result for 2010 is overall similar (a clear discontinuity around the threshold), although the fitted lines look different than for 2012. In this case, we can see readiness to buy getting smaller closer to the implementation week and decreasing even more afterwards. The differences in the patterns between 2012 and 2010 might be due to the fact that the 2010 reform was announced 9 months in advance, while the 2012 was only announced two months before.

On panel B, we show the effect on non-durable goods. In this case, there is no discontinuity around the threshold. Therefore, we do not find any evidence of intertemporal substitution for neither of the reforms. 
Table 3 Regression discontinuity (polynomial order 4): 2012 VAT reform impact on Google searches

Durable goods (Model I) Durable goods Non-durable goods (Model II)

\begin{tabular}{llll} 
Panel A: including week 0 & & & \\
2010 & $-5.6727^{* * *}$ & $-6.188^{* * *}$ & 0.3631 \\
& $(2.0143)$ & $(2.377)$ & $(3.2037)$ \\
2012 & $-6.4339^{* *}$ & $(5.572)$ & -1.7763 \\
& $(3.2595)$ & & $(4.3165)$ \\
Panel A: excluding week 0 & & $-8.480^{* * * *}$ & -0.81 \\
2010 & $-8.048^{* * *}$ & $(3.101)$ & $(4.75)$ \\
& $(3.053)$ & $-17.34^{* * *}$ & -3.001 \\
2012 & $-6.633^{*}$ & $(4.294)$ & $(4.258)$ \\
\hline
\end{tabular}

Model I includes all the keywords in Table 1, whereas Model II excludes those exempted goods

Standard error in parentheses

$* * * p<0.01 ; * * p<0.05 ; * p<0.1$

Table 4 presents the results of estimating the same model for the announcement and official approval dates and compares them with those of the implementation weeks. The results confirm that the main effect is found around the implementation week for both reforms. We find no significant effect around announcement and official approval weeks.

\subsection{Placebos and mechanism}

So far we have shown that Google searches related to readiness to buy durable goods change sharply around the implementation weeks. As a way to confirm that this change is actually due to the VAT tax reforms, Table 5 presents the results of the same model as in previous tables but using "IVA" (VAT) searches as the dependent variable. We estimate the model using both the announcement weeks and the implementation weeks. The results show that both around the implementation and the announcement weeks, there was a significant increase in searches right after the threshold date both in 2012 and also in 2010. This result together with the descriptive evidence shown previously in Fig. 3 points to consumers being aware and having in mind the new rates when making purchasing decisions over this period.

Table 6 presents the results of the different placebo tests. The table shows the estimates of the same model of previous tables but using different fake reform dates as thresholds. As there was no change in the tax rates around any of these fake thresholds, we should not see any change in search patterns if the effect that we are actually capturing in previous tables is due to the VAT reforms. Consistent with the results found in previous tables being causal, we do not find any significant effect around any of the $\pm 4, \pm 8$ and \pm 12 months thresholds. We do not find either any effect around 
Panel A: Durable goods
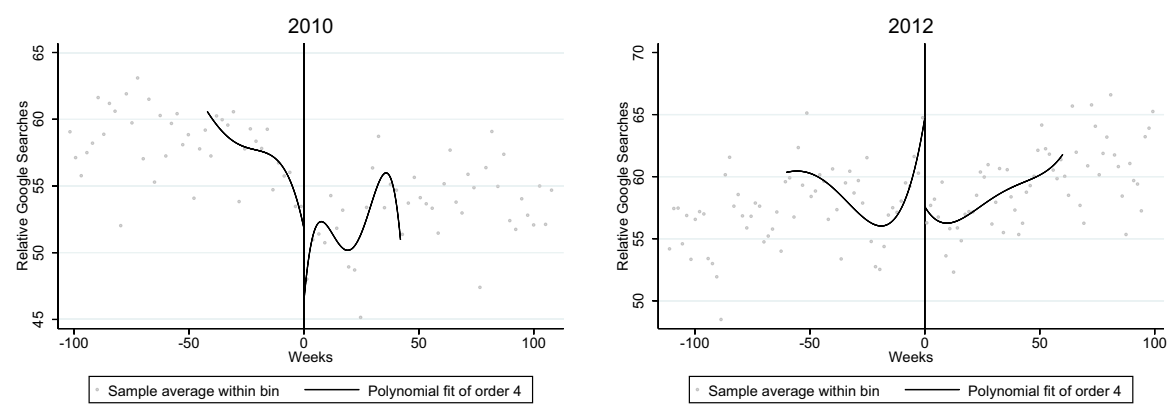

Panel B: Non-durable goods
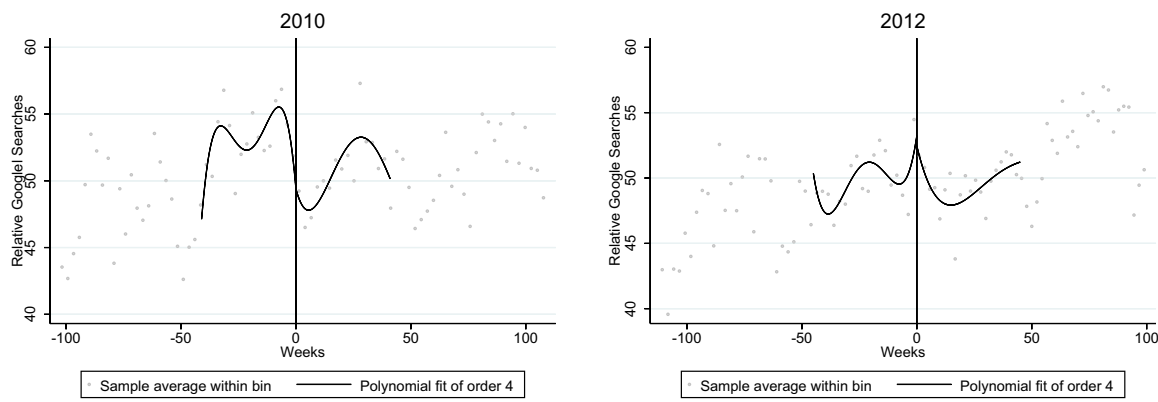

Fig. 4 Regression discontinuity (polynomial order 4): 2012 VAT reform impact on Google searches, by type of good

the announcement threshold. This is also expected as the announcement itself did not imply a change in the tax rates until a much later date.

\subsection{Extensions: the case of movie tickets}

Table 7 shows the differences-in-differences results of the effect of the reform of 2012 on the searches of movie tickets compared to video games. As explained before, a potential advantage of Google searches as a proxy for readiness to buy is that it allows us to study not just the effects of the reform on overall readiness to buy certain aggregate types of goods but also specific goods. Consistent with expectations, results show that the searches for movie tickets decreased significantly compared to those of video games right after the tax increase. It is worth noting that in this case, as we are using a differences in differences, our estimates capture the average treatment effect and not the effect at the threshold week. This result confirms the potential of the methodology to capture timely changes in readiness to buy patterns. According to our results, the worries of the movie industry regarding the negative effect of the VAT increase on the consumption of movie tickets were justified. 
Table 4 Regression discontinuity (polynomial order 4): VAT reforms impact on Google searches for durable goods-Model II-(timing of effect)

Table 5 Regression discontinuity (polynomial order 4): VAT reforms impact on Google searches for keyword "IVA"

\begin{tabular}{ll}
\hline Panel A: 2010 & \\
Announcement & -0.611 \\
(23 September 2009) & $(2.762)$ \\
Official approval & 2.815 \\
(BOE, 24 December 2009) & $(6.282)$ \\
Implementation & $-8.480^{* * *}$ \\
(01 July 2010) & $(3.101)$ \\
Panel B: 2012 & \\
Announcement (11 July 2012) and official approval & 4.681 \\
$\quad$ (BOE, 14 July 2012) & $(4.652)$ \\
Implementation & $-17.34 * * *$ \\
(01 September 2012) & $(4.294)$ \\
\hline
\end{tabular}

Standard error in parentheses

$* * * p<0.01$; ** $p<0.05 ;{ }^{*} p<0.1$

Panel A: 2010

$\begin{array}{ll}\text { Announcement } & 6.786^{* *} \\ \text { (23 September 2009) } & (3.382) \\ \text { Official approval } & 4.761 \\ \text { (BOE, 24 December 2009) } & (3.795) \\ \text { Implementation } & 8.877^{* *} \\ \text { (01 July 2010) } & \text { (4.482) }\end{array}$

Panel B: 2012

Announcement (11 July 2012) and official approval 11.80* (BOE, 14 July 2012)

Implementation

$40.345^{* *}$

(01 September 2012)

(18.903)

Standard error in parentheses

$* * * p<0.01 ; * * p<0.05 ; * p<0.1$

\section{Conclusions}

In this paper, we have estimated the effect of the increase in VAT tax rates in Spain on Google searches related to consumption, as a proxy of their readiness to buy. Our estimates show that the reform had a clear negative effect on those searches right after the implementation week compared to the previous weeks. Our placebo estimates show that the effect is indeed due to the reform. These findings are consistent with people's strategic timing of their purchasing behaviour and therefore with a pattern of intertemporal substitution of consumption.

One problem with the methodology is that searches themselves are not perfectly correlated with consumption. In certain situations, the amount of Google searches may be the same but purchasing behaviour different. For example, consumers may 
Table 6 Regression discontinuity (polynomial order 4): Placebo analysis for the 2012 and 2010 VAT reforms
Table 7 Differences-indifferences estimation about alternative leisure options (movie tickets vs. video games)

\begin{tabular}{lll}
\hline & 2010 & 2012 \\
\hline Placebo 4 months before & 1.6 & 3.503 \\
& $(2.629)$ & $(6.597)$ \\
Placebo 8 months before & 1.604 & -4.125 \\
& $(2.61)$ & $(4.342)$ \\
Placebo 12 months before & -0.892 & -3.011 \\
Placebo 4 months after & $(3.8)$ & $(2.739)$ \\
& -3.832 & -2.396 \\
Placebo 8 months after & $(2.624)$ & $(3.602)$ \\
Placebo 12 months after & -0.415 & 3.298 \\
& $(2.483)$ & $(3.375)$ \\
& 1.648 & -1.866 \\
\hline
\end{tabular}

Standard error in parentheses

$* * * p<0.01 ; * * p<0.05 ; * p<0.1$

\begin{tabular}{ll}
\hline Control variable: video games & $\begin{array}{l}\text { Treatment } \\
\text { variable: movie } \\
\text { tickets }\end{array}$ \\
\hline Treatment & $\begin{array}{l}-6.1964 * * * \\
(1.5237)\end{array}$ \\
Time* Treatment & $-12.9718^{* * *}$ \\
& $(2.2127)$ \\
\hline
\end{tabular}

Standard error in parentheses

$* * * p<0.01 ; * * p<0.05 ; * p<0.1$

search for durable goods in a similar amount before and after but buy cheaper goods after due to the tax rate. If this is the situation, using baskets of goods in the search dictionary that are highly aggregated would not be the right approach to measure readiness to buy because such level of aggregation would hide that consumers are buying cheaper options. In such cases, a more precise effect would be obtained by looking at specific types of goods.

In this regard, one of our extensions tests whether the reform had any significant effect on movie tickets (whose tax rate experienced a large change) compared to video games, whose tax rate changed only a little. We find that in this case, our method is able to capture a strong negative and significant effect that is persistent over time.

While using Google searches to capture readiness to buy has limitations, in this paper we show that it also has a large potential to capture policy effects.

Funding This study received the financial support of the Regional Government of Andalusia (Project SEJ 1512).

\section{Compliance with ethical standards}

Conflict of interest The authors declare that they have no conflict of interest. 
Ethical approval For this type of study, formal consent is not required.

Informed consent For this type of study, information from individual participants is not used so that this is not required.

Open Access This article is distributed under the terms of the Creative Commons Attribution 4.0 International License (http://creativecommons.org/licenses/by/4.0/), which permits unrestricted use, distribution, and reproduction in any medium, provided you give appropriate credit to the original author(s) and the source, provide a link to the Creative Commons license, and indicate if changes were made.

\section{References}

Angrist JD, Pischke JS (2008) Mostly harmless econometrics: an empiricist's companion. Princeton University Press, Princeton

Artés J, Jurado I (2018) Government fragmentation and fiscal deficits: a regression discontinuity approach. Public Choice 175(3-4):367-391

Attanasio O, Wakefield M (2008) The effects on consumption and saving of taxing asset returns. Prepared for the Report of a Commission on Reforming the Tax System for the 21st Century, Chaired by Sir James Mirrlees

Browning M, Crossley TF (2001) Luxuries are easier to postpone: a proof. J Polit Econ 108(5):1064-1068

Calonico S, Cattaneo MD, Farrell MH, Titiunik R (2017) rdrobust: software for regression discontinuity designs. Stata J 17(2):372-404

Camacho M, Pacce MJ (2018) Forecasting travellers in Spain with Google's search volume indices. Tour Econ 24(4):434-448

Crossley T, Low H, Matthew Wakefield M (2009) The economics of a temporary VAT cut. IFS Working Paper W09/02

D'Acunto F, Hoang D, Weber M (2016) The effect of unconventional fiscal policy on consumption expenditure. NBER Working Paper No. 22563

Della Penna N, Huang H (2009) Constructing consumer sentiment index for US using internet search patterns. Department of Economics, WP, 26

Feldstein M (2002) The role for discretionary fiscal policy in a low interest rate environment. NBER Working Paper No. 9203

Gelman A, Imbens G (2017) Why high-order polynomials should not be used in regression discontinuity designs. J Bus Econ Stat. https://doi.org/10.1080/07350015.2017.1366909

Gil M, Pérez J, Sánchez-Fuentes AJ, Urtasun A (2018) Nowcasting private consumption: traditional indicators, uncertainty measures, and the role of internet search query data. Working Paper $\mathrm{N}^{\circ} 1842$, Bank of Spain

Hall RE (2011) The long slump. Am Econ Rev 101(2):431-469

KMPG (2013) Informe Perspectivas España 2012

OCDE (2016) Consumption Tax Trends 2016 VAT/GST and excise rates, trends and policy issues

Shapiro MD (1991) Economic stimulant. Technical report, New York Times

Spanish Tax Agency, AEAT (2018) Monthly report of tax revenues, April, 2018

Publisher's Note Springer Nature remains neutral with regard to jurisdictional claims in published maps and institutional affiliations. 